\title{
El Proceso de Jesús visto por los Juristas
}

\author{
por el Consejero C. LAPLATTE, \\ Vocal de la Corte de Apelaciones de Colmar (Francia)
}

El proceso de Jesús seró siempre el proceso más grande de la Historia. Porque es el proceso de Dios. Pero, dentro del procedimiento, cparece como una desgraciada improvisación en la cual la incoherencia de la forma solo puede ser igualada por la iniquidad del fondo.

Con sus abundantes actas, con sus numerosos peritajes, con su lentitud, el proceso de Juana de Arco puede tener cierta apariencia de legalidad. Cuando hizo circular varias copias del expediente, Cauchon se hallaba sin duda en las disposiciones de un juez que, persuadido de haber dado un magnífico fallo, se apresura a enviarlo a las publicaciones jurídicas. ¡Pero el juicio de Cristo!.

Tan inciertas son las formas, que todavía se duda en afirmar quien ha condenado a muerte a Jesús. ¿Son las cutoridades judías de Jerusalén, con ratificación de su fallo por Pilatos? ¿Es solo Pilatos? Tal es la gran cuestión de derecho que plantea el drama del Catorce Nisan. Esta cuestión no podía dejar de llamar la atención de los juristas. Nada extraño, por consiguiente, que muchos entre ellos hayan tratado de resolverla, aportando, de esta manera, su contribución al estudio de la vida de Cristo, junto con los exegetas y los historiadores.

El más notable de los magistrados franceses del siglo XIX, el Fiscal General Dupin, publicó, en 1840, una pequeña obra, titulada "Jesús ante Caifás y Pilatos" en la cual estudia la cuestión bajo todos sus aspectos. Dupin llega a la conclusión que es solo Pilatos quien condenó a Jesús. Es también la tesis de dos profesores de historia del derecho: Regnault, autor de una erudita tesis titulada: "Una provincia pretoriana en los comienzos del Imperio romano", y Jean Imbert, profesor de la Facultad de Nancy, quien, en el Congreso de Derecho Canónico de 1947, presentó una ponencia, que llamó mucho la atención, sobre "Un punto de Derecho: ¿Es Pilatos quien condenó a Nuestro Señor Jesucristo?". (Âctas del Congreso, pág. 287).

(1) Publicado en la Revista "Ecclesia", de París. (NO 73 de 1954), I traducido del francés por Javier Kiefer-Marchand, con amable autorización del autor. 
La tesis contraria era la de Renón: Jesús fué condenado a muerte por el Sanhedrín, asamblea política y jurídica del pueblo judío; pero, como Palestina era entonces una zona ocupada, las condenas a muerte no podíon ser ejecutadas sinó después de haber sido ratificadas por lós autoridades romanas. Es por esto que al juicio judío siguió una instancia ante Pilatos quien, a pesar de su repugnancia, dió el exequatur a la sentencia pronunciada por los Judíos.

Es la tesis del exequatur. Generalmente es admitida en los manuales de instrucción religiosa.

Desde la detención de Cristo, se plantea el problema del concurso de las autoridades judías y romanas y de la parte que correspondió a cada una de ellas.

¿Por quién fué arrestado Jesús? Según el Padre Prat, autor de una obra muy encomiable sobre "Jesucristo", seguían a Judas, junto con gentes de la policía del Sanhedrín, soldados romanos. Los Evangelios "sinópticos" se refieren a "una turba provista de espadas y de palos, enviada por los sumos sacerdotes y los ancianos del pueblo". Naturalmente viene la tentación de decir: los que tenían espadas eran los soldados romonos, los que solo poseían palos eran los judíos. Desgraciadamente el episodio de San Pedro cortando la oreja de Malco, el servidor del gran sacerdote, nos prueba que los legionarios acuartelados en Jerusalén, no eran los únicos que podían en eso entonces llevar armas en la ciudad santa. Y, si San Pedro, persona privada, tenía una en su poder, con mayor razón los hombres de la guardia del Templo podían haber estado armados.

Estamos en una "zona ocupada". Sin duda, el ocupante no habría tolerado la existencia entre los ocupados de una fuerza armada considerable, pero bien podía haber autorizado un armamento reducido para las escasas fuerzas de policía local que subsistían en el país. Nosotros, que hemos vivido durante cuatro años bajo la ocupación, recordamos que nuestros gendarmes y nuestros policías habían conservado sus armas individuales: la palabra "espada" no es, por lo tanto, reveladora de la presencia de soldados romanos.

"Una turba provista de espadas y de palos"..., mal podemos ver al ejército romomo dentro de esta turba. El legionario en campaña no se junta con los civiles: si la guardia de la torre Antonia había sido encargada de la operación, habría instintivamente rechazado a esos guerreros improvisados. Un guía le habría bastado, Judas, y se habría puesto en marcha con método, discreción $\mathrm{y}$, sobre todo, con disciplina.

Es cierto que San Juan habla de "cchorte" y de "tribuno" o mós bien -puesto que San Juan escribia en griego de "Speira" y de "Chiliarchos". "Speira" era un cuerpo de tropa cualquiera. El "Chiliarchos" es, literalmente, un "jefe de mil", es decir un oficial al mando de un millar de hombres.

No fueron ciertamente necesarios mil legionarios -admitiendo que hubo uno solo- para apoderarse de Jesús: si los romanos estuvieron, es muy po- 
co probable que se hallaron bajo el mando de un oficial superior: tareas de esta naturaleza eran de la competencia de subalternos. Hay que admitir que este grado de "Chiliarchos" había sido atribuído port analogía al jefe de la guardia del templo. En los ejércitos de parada, que son casi siempre ejércitos de opereta, los galones se distribuyen generosamente.

La presencia en el texto de San Juan de las palabzas "Speira" Y "Chiliarchos" no constituye, pues, una prueba a favor de la participación del ejército romano; la débil presunción que se puede sacar en este sentido, es contradicha por otra, mucho más fuerte. que resulta de la fisonomía general del lugar, incompatible, como lo hemos constatado, con una hipótesis de la intervención del ejército romano.

No creemos, pues, en esta intervención, pero nos cuidaremos mucho de epilogar sobre esto a la manera del R. Padre Olivier quien se regacijaba de la abstención del ejército romano en la detención de Cristo, parque su participación habría "causado desmedro al honor militar, esta última forma de la virtud en las sociedades que se van". Cuando estas cosas fueron dichas, nos hallábamos en pleno asunto Dreyfus; algunos predicadores se preocupaban hasta en sus sermones del honor del ejército.

Es evidente que el drama de la Pasión fué preparado, urdido por el Sanhedrín; la responsabilidad moral de esta asamblea es, por consiguiente, indiscutible, pero este punto precisado, no prejuzga de la respuesta a la interrogación que hemos pianteado: ¿es ella que rindió el fallo, que pronunció la condena?

"Los Sinópticos" nos dicen que, después de haber sido llevado ante Anós, que lo envió ante su yerno Caif́́s, Jesús compareció "al amanecer ante el Sanhedrín, cuyos miembros resolvieron por unanimidad que mere. cia la muerte".

Después de lo cual, estas gentes "todas en grupo", nos dice San Lucas, llevaron a Jesús ante Pilatos. Este salió a su encuentro, ya que ellos, (para no mancillarse) no ingresaron al pretorio, y les preguntó: “¿Qué acusación formulais contra este hombre?". $\AA$ esta pregunta contestan con esta declaración: "Si éste no fuere un malhechor, no te lo habríamos entregado". Pero, la respuesta no tarda: "Tomadlo vosotros y juzgadlo según vuestra ley".

Los que conocen el procedimiento judicial, saben que no se da la importancia suficiente a la competencia de un tribunal, es decir a las condiciones bajo las cuales un juicio es diferido a una jurisdicción.

La escena que acabamos de mencionar, siguiendo literalmente a los Evangelios, nos hace conocer de manera precisa y clara como Pilatos se hizo cargo del juicio de Jesús: las gentes del Sanhedrín se constituyen en acusadores. Pilatos, que trata de inhibirse, les devuelve el asunto diciéndoles que lo juzguen ellos mismos.

¿Es este procedimiento compatible con la tesis del exequatur?

El exequatur es un procedimiento al cual se recurre para hacer conferir a una decisión de un tribunal extranjero fuerza de ejecución. En el 
presente caso, no se trataba propiamente de una sentencia extranjera, pero se nos dice que las decisiones del Sanhedrín que implicaban condena a muerte, no podían ser ejecutadas sinó después de haber sido sometidas a la ratificación de la cutoridad romana.

Si tal había sido el caso en el proceso de Cristo, ¿es fácil ver que el procedimiento habria isido entonces muy distinto? Ias gentes del Sanhedrín habría dicho a Pilatos: "Este hombre ha sido condenado a muerte por nosotros $y$ venimos a pedirte que ratifiques esta sentencia para que sea ejecutada. Dá el exequatur".

Y Pilatos no habría tenido la ingenuidad de decirles: "Juzgad a este hombre", puesto que esto ya se había hecho.

Sin duda, las gentes del Samhedrín contestan a la invitación que les hace el Procurador romono para que juzguen el asunto, diciendo que no les es permitido dar muerte $a$ nadie, pero, al decirlo, no han declarado de ninguna manera que ya habían pronunciado una sentencia de muerte $Y$ que solo pedían su confirmación. Es solicitar el texto, interpretando de esta manera el propósito.

Y el resto del juicio nos confirma en nuestra opinión que se trataba del primer juicio: de un juicio anterior que habrian contenido los motivos de la condena, no hay ninguna referencia. En cambio, las gentes del Sanhedrín sostienen sus acusaciones, y Pilatos instruye a fondo el asunto, como cuando un juez tiene frente $\alpha$ él $\alpha$ un inculpado y no $\alpha$ un hombre ya juzgado.

¡Pero, es más aún! Pronto se produce un incidente dentro del procedimiento que condena sin apelación la tesis de Renón. Después de haber tratado de deshacerse del asunto invitando al Sanhedrín a tomarlo a su cargo, he aquí que lo trasfiere a Herodes, Tetrarca de Galilea, que se hallaba entonces en Jerusalén.

Si Pilatos habria sido solamente llamado a ratificar una sentencia ya pronunciada, no podía remitir el asunto a un príncipe judío que, por ningún motivo, podía conferir $\alpha$ este juicio el exequatur, privilegio de la potencia ocupante! Nos hallamos frente $\alpha$ una evidencia que salta $\alpha$ la vista.

El episodio de Herodes es un "conflicto negativo de atribución", puesto que el Tetrarca, después de haberse burlado de Cristo, lo devolvió nuevamente a Pilatos.

Sigamos el desarrollo del procedimiento. Pilatos propone a los acusadores de Cristo una transacción: haró castigar a Jesús, $y$ lo pondrá luego en libertad.

Esta solución nó se concilia con la tesis del exequatur: un tribunal a quien se presents una solicitud àe exequatur, da curso al pedido o lo rechaza. Una conmutación de pena no puede ser el resultado de este procedimiento: si Pilatos se habría negado a ratiticar la condena a muerte, el Sanhedrín habría tenido que juzgar nuevamente $\alpha$ Cristo y condenarlo, él mismo, a otra pencr.

La violenta presión que se ejerce después sobre Pilatos y que va creciendo, no debe producir ilusiones: la cctitud pasiva del Procurador, que cede cada vez más a los clamores de los acusadores de Cristo, no debe disimular este hecho que es él quien, finalmente, pronuncia la condena $\alpha$ 
muerte como es él quien, antes, condenó a Jesús al suplicio de la flageIación.

Es Pilatos quien redactó el "titulus", leyenda indicando los motivos de la condena y que será colocada en la cruz sobre la cabeza de Jesús.

Y, para subrayar el carócter romono de la condena, Jesús padecerá el suplicio de la crucifixión, que es un suplicio romano. Por fin, son soldados romanos, a las órdenes de un centurión, y no los "milicianos" de la guardia del templo, los que formarán la escolta.

Nuestra conclusión sigue de lo que antecede. Jesús fué condenado a muerte por Pilatos, $y$ únicamente por Pilatos, $\alpha$ pedido $y$ bajo la presión del Sanhedrín.

Esta es una conclusión jurídica, estrictamente jurídica y adivinamos que gran número de lectores juzgarán que esta sutileza nada cambia al fondo de la cuestión, es decir a las realidades morales y sicológicas del drama.

Convenimos en ello: acusar es ya juzgar y la acusación calumniosa hace llevar a su autor el peso del error judicial que ha hecho cometer al juez.

Pero, en el presente caso, no se trata de un error judicial, puesto que Pilatos sabía que Jesús era inocente ("no hallo ningún crimen en este hombre"): la condena es pues una iniquidad. vaciones:

Sobre las responsabilidades de los acusadores haremos dos obser-

La primera es que se debe interpretar el término "judíos" que emplean los Evangelios. Cuando San Juan escribe: "Los Judíos se pusieron a gritar "Matadlo, Crucificadlo", es evidente que la palabra solo se aplica a los individuos presentes. Daniel Rops ha hecho, juiciosamente, la observación en "Jesús y su tiempo": "Los Judíos que estaban allí eran Judíos...".

¿Cuántos eran? Nadie los ha contado. Sin embargo, podemos formarnos una idea aproximada de su número considerando el lugar don. de se hallaban.

Era el patio interior de la fortaleza Antonia. San Juan designa este lugar diciendo: "El tribunal de Pilatos (se hallaba) en el lugar llamado Lithostratos, en hebreo Gabbatha".

No era el Pretorio; las gentes del Sanhedrín no habian querido penetrar allí para no ser mancillados legalmente en ese día próximo a ia pascua. Pilatos se hallaba, al aire libre, en su tribunal, es decir sobre una tribuna.

Gracias a un descubrimiento del Padre Lagrange, hemos podido nuevamente recorrer el suelo de ese lugar. $Y$ conocemos sus dimensiones: $2.500 \mathrm{~m} 2$.

Y, según Daniel-Rops, el público no se hallaba aún en ese espacio restringido: el temor de ser mancillados habría retenido a los Judíos fuera 
de ese patio; se aglomeraban ante la puerta $y$ en los lugares inmediatos. En este punto, no coinciden con lo expuesto por Daniel-Rops; el diálogo entre Pilatos y los acusadores de Cristo, la enorme presión que estos ejercen sobre los debates se explican muy difícilmente si se admite que el público se hallaba alejado en los extremos del Lithostratos.

Al leer el Evangelio, se percibe que los enemigos de Jesús estón alli, muy cercanos, y que forman una masa en un frente bastante extendi. do: nada pierden del juicio e intervienen constantemente como los abogados en un proceso.

Por otra parte, si San Marcos nos dice que el pueblo había venido ante el Pretorio (XV, 8) y si San Juan nos hace saber que los acusadores no entraron al Pretorio (XVIII, 28), ningún texto excluye la presencia del público en el Lithostratos. San Juan nos dice (XVIII, 33) que en cierto momento Pilatos ingresó con Jesús al interior del Palacio (probablemente en el Pretorio), para interrogarlo frente a trente, como hace un juez instructor. ¿Si el Lithostratos habría estado sin público, por qué se habría retirado? Habría bastado con cerrar las puertas.

Por fin, esta frase de San Juan: "Pilatos vino a encontrarlos afuera" (XVIII, 29), mal concuerda con la dignidad del Procurador si se debe admitir que Pilatos salió a la calle para hablarles. Pero todo encuadra perfectamente, si se admite que Pilatos hizo colocar su tribunal al aire libre sobre la esplanada del Lithostratos, para permitir a los acusadores sostener su acusación, sin ser mancillados.

No es necesario reunir a miles de individuos para producir un efecto masivo capaz de intimidar a un Procurador de corácter débil.

Es evidente que todo el Lithostratos no estaba a la disposición del público; había el "tribunal" de Pilatos, que me represento rodeado de guardias: se hallaba Jesús a distancia respetuosa del juez, y también rodeado de guardias; los asistentes se hallaban más lejos, mantenidos por un cordón de soldados. La majestad del Imperium se traducía por un gran espacio libre: no sucedía lo que sucede en nuestros tribunales correccionales donde los curiosos se apoyan sobre el sillón del Presidente; se respetaban las distancias y esto reducía el espacio reservado al público; estimamos que éste era de algunos centencres de individuos, lo que era suficiente para influir sobre los debates; era un porcentaje ínfimo con relación a la población total de Jerusalén, muy aumentada entonces por las peregrinos llegados en vísperas de Pascua.

La segunda observación se refiere a una palabra de Cristo, que condena a sus acusadores. Respondiendo a Pilatos que le había dicho: "¿Ignoras que tengo el poder de crucificarte y también el poder de darte libertad?". Jesús declaró: "No tendríais ningún poder sobre mí, si no os habría sido dado desde arriba. $\mathrm{Y}$ es por eso que el que me ha entregado a vos es más culpable".

Los exegetas han tratado de comprender el final: ¡no saben cómo relacionarlo con lo que cutecede!

El "es por eso", crea la dificultad, escribe el Padre Prat, que nos habla de los "comentarios infinitos", a los cuales esta palabra de Cristo ha dacio lugar, $y$ que, dice, no los han esclarecido mucho. 
Ninguno de estos sabios comentaristas había comparecido ante un tribunal correccional. De lo contrario, habrían inmediatamente admitido la clave de la dificultad, 0 , más bien, se habrían convencido que no existía tal dificultad.

$\mathrm{Si}$ el poder de jurisdicción que ejerce Pilatos viene de alguien más alto que él, es decir de Dios, los que, al acusar $\alpha$ un inocente ante su tribunal le hacen cometer un error judicial, llevan la responsabilidad, no solo de la sangre inocente que va a ser injustamente vertida, sino también del ultraje a la autoridad de Dios que cometen al provocar un error de parte de un poder que emona de ella.

Gentes que llevan acusaciones temerarias, que hacen actuar a la policía y a la justicia, son, en nuestros días, acusados de desacato. Este delito es, con mayor razón, evidente si la denuncia es causa de una aberración de la justicia que causa daño a su prestigio.

En el presente caso, las falsas acusaciones presentadas por los Judios ultrajan a la justicia y al autor de toda justicia de quien los jueces de la tierra son los delegados. Las palabras "es por eso" quedan pues debidamente acloradas.

La palabra final la hallaremos en el Catecismo.

Se trata muchas veces con grandes principios de hacer recaer las responsabilidades jurídicas y las responsabilidades morales, sobre tal o cual persona. Este punto de vista constituyó una negación del plan de la Redención: ¿para qué buscar un "pueblo deicida", cuando es el pecado - por consiguiente los pecadores- los que son los verdaderos deicidas? El culpable hay que buscarlo en cada uno de nosotros, y no en un pueblo - en un magistrado, que fueron solo sus instrumentos. 